\title{
Unravelling riverine microbial communities under wastewater treatment plant effluent discharge in large urban areas
}

\author{
Yang Huo ${ }^{1,2}$ - Yaohui Bai ${ }^{1}$ Jiuhui $Q u^{1}$
}

Received: 21 March 2017 / Revised: 4 June 2017 / Accepted: 9 June 2017 / Published online: 5 July 2017

(C) Springer-Verlag GmbH Germany 2017

\begin{abstract}
In many highly urbanized areas, effluent from wastewater treatment plants (WWTPs) represents a significant proportion of the water source for receiving rivers. Microbial communities are major components of riverine ecosystems and mediate the processes of nutrients and organic matter produced by treated and untreated WWTP effluent. To date, the impacts of WWTP effluent discharge on riverine microbial communities remain poorly understood. Based on 16S rRNA gene sequencing and water quality analysis, we investigated the microbial community compositions and predicted functions in the effluents of five municipal WWTPs and their receiving rivers. The results showed that the microbial compositions in the five WWTP effluents with different treatment processes were similar. Significant differences in the microbial community were not noted between the effluent, upstream, and downstream sites for both sampling months. However, dissimilarity of microbial composition between two sampling periods was observed. The temperature, $\mathrm{pH}$, dissolved oxygen, and ammonium were major environmental factors associated with microbial community changes. Functional annotations of microbial communities based on $16 \mathrm{~S}$ amplicons identified xenobiotic degradation and
\end{abstract}

Electronic supplementary material The online version of this article (doi:10.1007/s00253-017-8384-4) contains supplementary material, which is available to authorized users.

Jiuhui Qu

jhqu@ rcees.ac.cn

Yang Huo

huo0814@outlook.com

1 Key Laboratory of Drinking Water Science and Technology, Research Center for Eco-Environmental Sciences, Chinese Academy of Sciences, Beijing 100085, People's Republic of China

2 University of Chinese Academy of Sciences, Beijing 100049, China metabolism functions in effluent and river samples. Quantitative polymerase chain reaction revealed the dominance of ammonia-oxidizing bacteria (AOB) over ammoniaoxidizing archaea (AOA) in the WWTP effluents and rivers, and significant positive correlation between AOB abundance and nitrate concentration was observed. These findings will help increase our understanding of the impact of effluent discharge on urban river ecosystems.

Keywords WWTP effluent $\cdot$ Receiving river $\cdot$ Microbial community $\cdot$ High-throughput sequencing

\section{Introduction}

Wastewater treatment plants (WWTPs) carry large loads of domestic and industrial wastewater and frequently discharge effluent into open lotic ecosystems. Despite a series of treatment processes, WWTP effluent still contains contaminants such as nutrients and emerging micropollutants (Schwarzenbach et al. 2006). Previous studies have revealed the ecosystem impacts of WWTP effluent, including increased nutrient loading (Waiser et al. 2011), eutrophication (Gucker et al. 2006; PernetCoudrier et al. 2012), and community structure disruption of algae, invertebrates, and fish (Bunzel et al. 2013; Dyer et al. 2003; Spanhoff et al. 2007). These detrimental effects have increased public environmental concern and pose threats to both riverine and human health. Evaluating and predicting aquatic responses to WWTP effluent, notably in urbanized watersheds in arid and semi-arid regions where river flows are perennially dominated and dependent on WWTP effluent (Brooks et al. 2006), is a continuing challenge.

As the economic and political center of China, Beijing is a good representative to assess the impacts of WWTP effluent on receiving river ecosystems. Beijing is one of the fastest growing 
municipalities and suffers intense pressure from water scarcity and wastewater discharge. The city's average annual precipitation is only $590 \mathrm{~mm}$, compared with $1090 \mathrm{~mm}$ in New York at the same latitude (Probe International Beijing Group 2010). In 2014, Beijing discharged 1.61 billion cubic meters of wastewater, $86.1 \%$ of which was treated by 15 central municipal WWTPs (Beijing Water Authority 2014). Five of Beijing's largest WWTPs (Qinghe, Beixiaohe, Jiuxianqiao, Gaobeidian, and Xiaohongmen) treat approximately 2.28 million cubic meters of wastewater daily and account for $90 \%$ of Beijing's treated wastewater discharge into the tributaries of the Haihe River System (HRS) (Qi et al. 2015). The HRS connects two megacities in the North China Basin (Beijing and Tianjin), and $95 \%$ of the river water from the HRS is diverted for agricultural irrigation.

Ubiquitous and highly abundant microorganisms in streams and rivers can mediate carbon and nutrient cycling (McClain et al. 2003) and organic matter decomposition (Logue et al. 2016; Tank et al. 2010). Although the relationship between WWTP discharge and river ecosystem health has been widely investigated, previous findings have been primarily based on macroinvertebrate bioindicators (Prat et al. 2013; Wright et al. 1995). Research on riverine microbial communities was largely restricted due to conventional cultivation-dependent techniques. In recent years, high-throughput 16S rRNA gene sequencing has become a widely employed tool for assessing composition (Sergeant et al. 2012) and functional profiles (Arndt et al. 2012; Asshauer et al. 2015; Langille et al. 2013) of microbial communities. Several studies have explored the effect of WWTP effluent on the composition and function of microbial communities in the receiving river (Atashgahi et al. 2015; Drury et al. 2013; Marti and Balcazar 2014; Wakelin et al. 2008). However, more research are still needed especially for riverine ecosystem in large urban area, which is much influenced by WWTP effluent treated by various techniques. In this study, we attempted to address several issues, including (1) whether microbial community composition in WWTP effluent varies by different treatment techniques; (2) whether WWTP effluent microbial communities are significantly different from river communities; and (3) which environmental factor(s) is/are strong driving force(s) for changes in WWTP and riverine microbial communities. We applied $16 \mathrm{~S}$ rRNA gene-based sequencing for the identification of microbial communities in effluent from the five largest WWTPs of Beijing and their receiving rivers. The structural and functional profiles of the microbial communities in these sites were analyzed using a series of bioinformatics tools.

\section{Materials and methods}

\section{Sampling of the WWTP effluents and receiving rivers}

The waterways of the receiving rivers and sampling sites in this study are shown in Fig. S1. All these rivers discharge into the Wenyu River, upper reach of the HRS. The characteristics of the five WWTPs and the receiving rivers are described in Table S1. The geopositions of the sampling sites are shown in Table S2. Sampling campaigns were performed in the end of April and November 2015 without recent rainfall. For each WWTP and its receiving river, we selected five sampling sites: the effluent, two sites upstream of the effluent outfall, and two sites located downstream of the discharging point (E, U1, U2, $\mathrm{D} 1$, and D2). The distance of each sampling site was at least $150 \mathrm{~m}$ for adequate mixing of effluent and river water. For each site at each sampling time, a 10-L surface water sample was collected using sterile containers. Temperature and $\mathrm{pH}$ were measured in the field using an ULTRAMETER II $^{\mathrm{TM}}$ 6PFC ${ }^{\mathrm{E}}$ (MYRON L Company, Carlsbad, CA, USA). Dissolved oxygen (DO) was measured by a HQ30d portable meter with an LDO101 probe (HACH, Loveland, CO, USA). The collected samples were immediately placed at $4{ }^{\circ} \mathrm{C}$ in the dark for further processing. Selected physicochemical parameters, including total phosphorus and nitrogen (TP, TN), soluble phosphate $\left(\mathrm{PO}_{4}\right)$, ammonium and nitrate $\left(\mathrm{NH}_{3}-\mathrm{N}, \mathrm{NO}_{3}-\right.$ $\mathrm{N}$ ), total organic carbon (TOC), and chemical oxygen demand (COD) were analyzed using methods provided by the State Environmental Protection Administration of China (See Table S3 for details).

\section{DNA extraction and 16S rRNA gene sequencing}

Prior to DNA extraction, each water sample was filtered using a $0.45-\mu \mathrm{m}$ pore size cellulose nitrate membrane on a vacuum pump. Total environmental DNA was extracted from the membranes in triplicate using a PowerWater DNA isolation kit (Mo-Bio Laboratories, Carlsbad, CA, USA). Successful extraction was confirmed by agarose gel electrophoresis. Prepared DNA was stored at $-80{ }^{\circ} \mathrm{C}$ until further analysis. The extracted DNA samples were used for 16S rRNA gene sequencing. The V4 region of the $16 \mathrm{~S}$ rRNA gene was amplified using primers 515F (5'-GTGCCAGCMGCCGCGGT AA-3') and 806R (5'-GGACTACHVGGGTWTCTAAT-3') with dual index and Illumina adapters for polymerase chain reaction (PCR). Targeted PCR amplicons were sequenced on a MiSeq platform (Illumina, Carlsbad, CA, USA), which produced $2 \times 250$ bp paired-end reads. The raw sequence data can be accessed from the NCBI Sequence Read Archive (SRA) with accession number [SRA:SRP068719].

\section{Bioinformatics analysis for community composition}

The Illumina paired-end sequences were processed using the UPARSE + QIIME pipeline (Pylro et al. 2014). In brief, forward and reverse Illumina reads were merged with QIIME v1.9.0 (Caporaso et al. 2010). USEARCH was used for dereplication and filtering of noisy sequences and chimeras (Edgar 2010). The operational taxonomic unit (OTU) 
clustering was performed by the UPARSE method (Edgar 2013) and then assigned to taxonomy using uclust with a 97\% sequence identity threshold. Representative sequences were aligned against the Greengenes database May 2013 release (DeSantis et al. 2006). Alpha diversity was calculated using the Chao 1 (Chao 1987) and Shannon diversity indices. Unweighted-Unifrac beta diversity was determined using QIIME and analyzed by non-metric multidimensional scaling (NMDS). The relationship between environmental variables and log-transformed OTU abundances was analyzed through redundancy analysis (RDA), and their pairwise Pearson's $r$ correlations were calculated using QIIME.

\section{Taxonomy-based functional prediction of microbial communities}

To determine the putative functional profiles of the microbial communities based on 16S rRNA gene data, we performed taxonomic-to-phenotypic mapping by METAGENassist, a web-based tool for comparative metagenomic analysis (Arndt et al. 2012). To further investigate the organic pollutant degradation and metabolism profiles in the five zones, we applied PICRUSt (Langille et al. 2013), another 16S rRNA gene functional prediction tool. Functional predictions were aligned in the Kyoto Encyclopedia of Genes and Genomes (KEGG) database, and the functional parameters were assigned to Tier 3 . The predicted results were then analyzed with STAMP software v2.1.3 (Parks et al. 2014) and plotted using pheatmap package in $\mathrm{R}$ (version 3.2.3). Functional analyses were performed following the corresponding online tutorials (METAGENassist: http://www.metagenassist.ca/ METAGENassist/faces/

Docs/Tutorial.jsp; PICRUSt: http://picrust.github.io/ picrust/tutorials/

metagenome_prediction.html\#metagenome-predictiontutorial).

\section{Quantification of ammonia-oxidizing microbes by real-time PCR}

The quantitative distributions of bacteria, archaea, ammoniaoxidizing bacteria (AOB), and ammonia-oxidizing archaea (AOA) in the river, and WWTP effluents were determined by real-time PCR. Bacterial and archaeal $16 \mathrm{~S}$ rRNA or amoA genes were quantified by the LightCycler96 real-time PCR system (Roche, Switzerland) using the SYBR Green I method (Noble and Fuhrman 1998). Information on the primer pairs and thermal programs are provided in Table S5. Standard DNA plasmids for absolute quantification were prepared as previously established (Bai et al. 2012). The real-time PCR reaction mixture $(20 \mu \mathrm{L})$ contained $1 \mu \mathrm{L}$ of template DNA, $0.4 \mu \mathrm{L}$ of each primer, $10 \mu \mathrm{L}$ of $2 \times$ FastStart SYBR Green Master (Roche, Switzerland), and $8.2 \mu \mathrm{L}$ of $\mathrm{dH}_{2} \mathrm{O}$.
Each sample was performed in triplicate. The qPCR efficiencies ranged from 93 to $108 \%$, and the linear regression of amplification efficiency $\left(R^{2}\right)$ was all over 0.99 . The relationship between log-transformed amoA gene abundance and concentrations of $\mathrm{NH}_{3}-\mathrm{N}$ and $\mathrm{NO}_{3}-\mathrm{N}$ was analyzed. The Glejser test was performed to detect data heteroscedasticity (Glejser 1969). A Spearman's correlation was also calculated to identify the linear relationship between $\mathrm{AOB}$ abundance and concentration of $\mathrm{NO}_{3}-\mathrm{N}$.

\section{Results}

\section{Physicochemical properties of WWTP effluent and river samples}

The physicochemical properties of the water samples are summarized in Table S3. The water temperature ranged from 18.3 to $24.0^{\circ} \mathrm{C}$ in April and from 3.7 to $14.5^{\circ} \mathrm{C}$ in November. The $\mathrm{pH}$ varied between 7.16 and 8.54. The concentrations of $\mathrm{NH}_{3}-$ $\mathrm{N}$, TP, and TN revealed high nutrient levels at most sampling sites compared with those of the Chinese Environmental Quality Standards for Surface Water (GB 3838-2002). To investigate the impact of effluent and sampling time on river water quality, a two-way analysis of variance (ANOVA) was performed. The results showed that the effluents did not significantly alter the nutrient level of the receiving rivers although concentrations of $\mathrm{NO}_{3}-\mathrm{N}(P<0.01), \mathrm{TN}(P<0.01)$, and TP $(P<0.01)$ in November samples significantly increased and concentrations of TOC in November samples significantly decreased $(P<0.01)$. These findings suggest that WWTP effluent did not induce significant changes between upstream and downstream, which might be due to the upstream sites being dominated by previously discharged WWTP effluent.

\section{Alpha and beta diversity of the microbial communities}

Using Illumina paired-end 16S rRNA gene sequencing, a total of $1,814,055$ raw sequences were produced, including $1,703,308$ high-quality reads with an average merged length of $253 \mathrm{bp}$ after processing. The sequences were clustered into a total of 8383 OTUs at the $97 \%$ similarity level, with a Good's library coverage from 97.7-99.3\%. Rarefaction curves revealed that bacterial diversity almost reached a saturated sequencing depth (Fig. S2). Sequence libraries for the sites in April ranged between 446 and 1477 OTUs, and in November ranged between 557 and 1929 OTUs. The rarefaction curve, Chao 1 value, and Shannon index were calculated as metrics for species richness and diversity (Fig. S2). The lowest and highest Chao 1 values were found downstream of BXH and upstream of JXQ, respectively, indicating distinct diversity between these sites in regard to microbial 
community richness. Beta diversity was visualized via NMDS (Fig. 1). The NMDS graph showed clear and significant differences in bacterial community composition between the two sampling periods for most of the riverine samples (ANOSIM, $P<0.01)$. However, no consistent significant differences between the upstream and downstream sites in both seasons were observed at most sampling sites, revealing that effluent did not significantly change in microbial compositions. Only the bacterial community composition at downstream of Xiaohongmen was more similar to its effluent in both seasons, suggesting that bacterial community composition of Xiaohongmen was influenced by its effluent. Additionally, most effluent samples were closely clustered in both seasons at Gaobeidian, Jiuxianqiao, and Qinghe, indicating little composition variability in the microbial community among these effluent sites (Fig. 1).

\section{Microbial community composition and functional characterization}

From the OTU assignment, a total of 57 phyla, 155 classes, and 924 genera were identified across all samples. The dominant taxa based on classes with more than $1 \%$ relative abundance are summarized in Fig. 2. Proteobacteria (41-82\%) and Bacteroidetes (7-39\%) were the most abundant phyla in almost all samples. Within Proteobacteria, Betaproteobacteria dominated in most April and most November samples (2055\%). Epsilonproteobacteria and Gammaproteobacteria were more abundant in November samples (Fig. 2). In
Bacteroidetes, Flavobacteria, and Bacteroidia dominated at most sampling sites. These results indicate that effluent discharge did not alter the microbial community composition between upstream and downstream. In addition, 21 OTUs were identified as core microbial taxa present across all samples (Table S4). Comamonadaceae was the largest family found in the Betaproteobacteria class and contributed more than a quarter of the total core community. The genera Arcobacter and Flavobacterium were also identified as abundant taxa in the core community.

Putative changes in microbial community function based on composition were predicted by METAGENassist (Fig. 3). Two functions that are assigned as a characteristic of the greatest number of $16 \mathrm{~S}$ rRNA sequences, on average, were annotated as ammonia oxidizers (12,598 sequences) and sulfur oxidizers (9653 sequences), indicating possible involvement of ammonia and sulfur oxidizer microbes in the samples. For pollutant metabolism and degradation profiles, a high number of $16 \mathrm{~S}$ rRNA sequences were assigned to degradation of aromatic hydrocarbons and xylan (2787 and 3406 sequences on average, respectively). Atrazine degradation, chlorophenol degradation, and naphthalene degradation were also identified in river and effluent samples. Functional properties with xenobiotic degradation and metabolism (XDM) were further investigated by PICRUSt assigned up to level 3 in the KEGG database (Fig. S3). We identified 8 out of 20 XDM features with statistical significance, including bisphenol degradation $(P<0.01)$ and polycyclic aromatic hydrocarbon degradation $(P=0.02)$. A high percentage of
Fig. 1 Non-metric multidimensional scaling (NMDS) biplot showing the beta diversity among five WWTP effluents and their receiving rivers. Samples collected in April and November are in light blue and orange, respectively. Sampling sites are connected with lines of different dash types according to their locations and displayed in different shapes (upper triangle: upstream sites; lower triangle: downstream sites; circle: effluent sites)

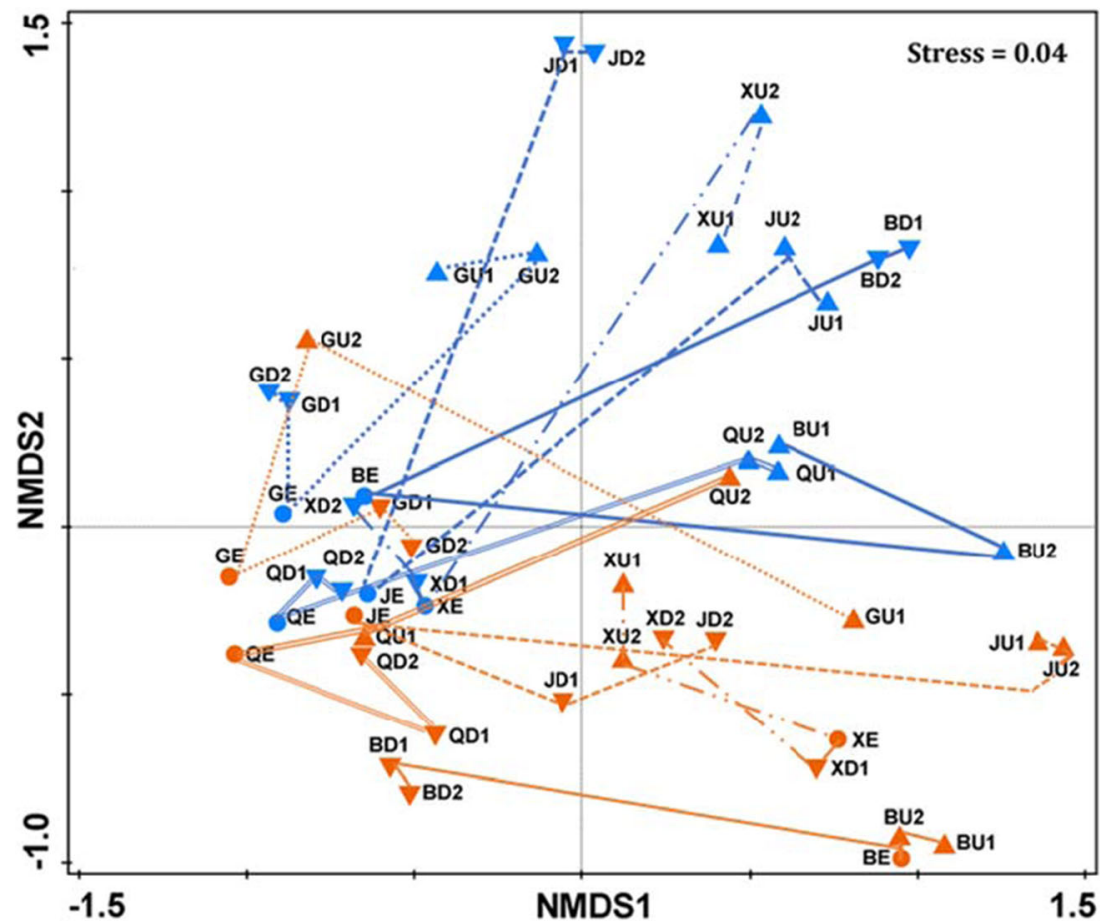


April

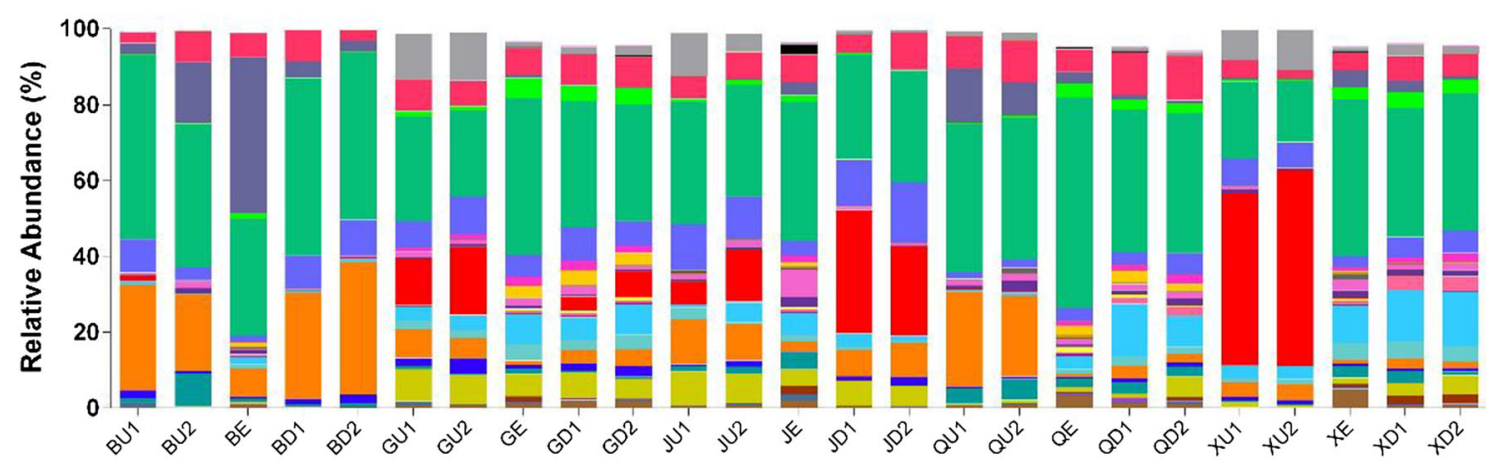

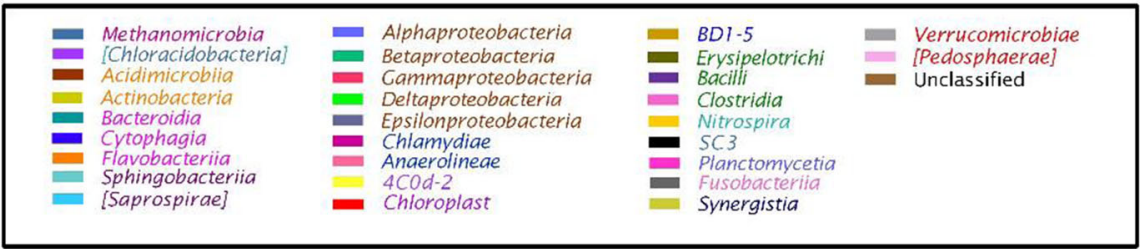

November

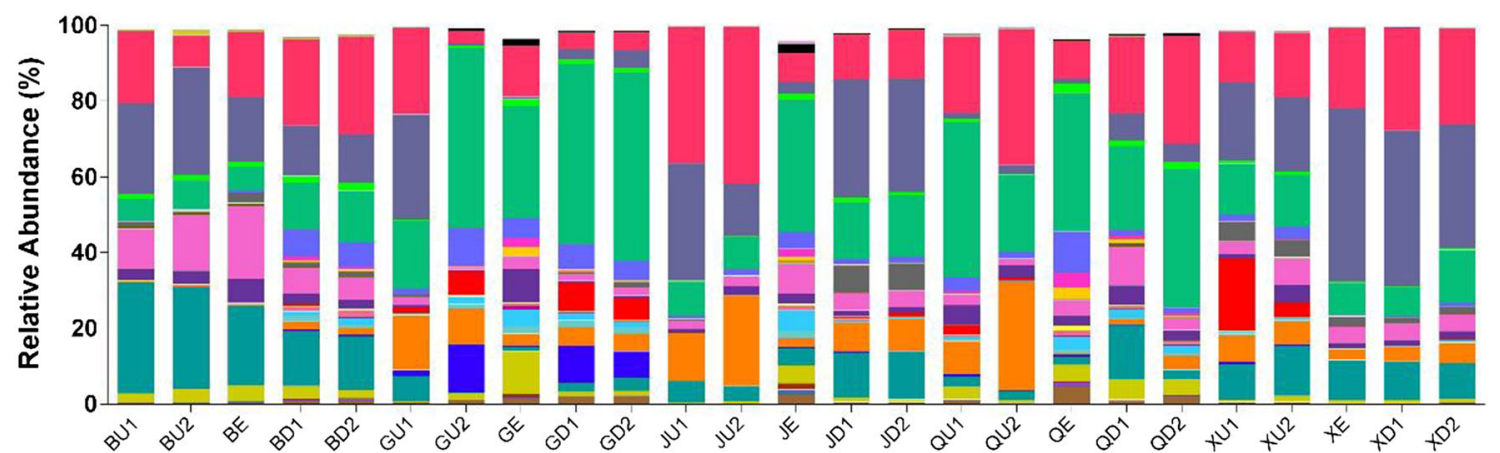

Fig. 2 Relative abundances of microbial communities (classes) among the five sampled effluents and rivers in April and November. Taxa that accounted for less than $0.1 \%$ of the relative abundance or present in less than three samples were omitted from the chart. Text colors in the legend represent different phyla sequences were assigned to caprolactam degradation and chloroalkane and chloroalkene degradation. These findings reveal that microbes in the effluents and rivers were possibly involved in the degradation and metabolism of a variety of organic pollutants. However, neither seasonal nor regional associations were found among these functional profiles.

\section{Relationship between environmental variables and microbial communities}

RDA was performed to gain an overview on the associations between physicochemical water characteristics and microbial community composition (Fig. 4). Forward selection tests indicated that temperature $(P<0.01), \mathrm{pH}(P<0.01)$, DO $(P<0.01)$, and $\mathrm{NH}_{3}-\mathrm{N}(P<0.01)$ were the four main environmental variables (total percentage of contribution $=71.7 \%$ ) that accounted for changes in the bacterial communities with statistical significance. Ten bacterial classes that best fit the RDA were analyzed. Alphaproteobacteria and Betaproteobacteria were positively associated with $\mathrm{pH}$ and temperature, whereas Gammaproteobacteria, Epsilonproteobacteria, and Fusobacteria were affected by variability of nutrients. Relationships between environmental factors and other bacterial classes were investigated by calculating a Pearson's $r$ correlation (Fig. S4). Acidimicrobiia, Anaerolineae, and Pedosphaerae were positively associated with $\mathrm{pH}(r=0.37, P<0.01 ; r=0.39, P=0.01 ; r=0.34$, $P=0.02$, respectively). Alphaproteobacteria and Chloroplast were negatively correlated with $\mathrm{NO}_{3}-\mathrm{N}(r=-0.28, P=0.04$ and $r=-0.27, P=0.05$, respectively). Negative correlations 

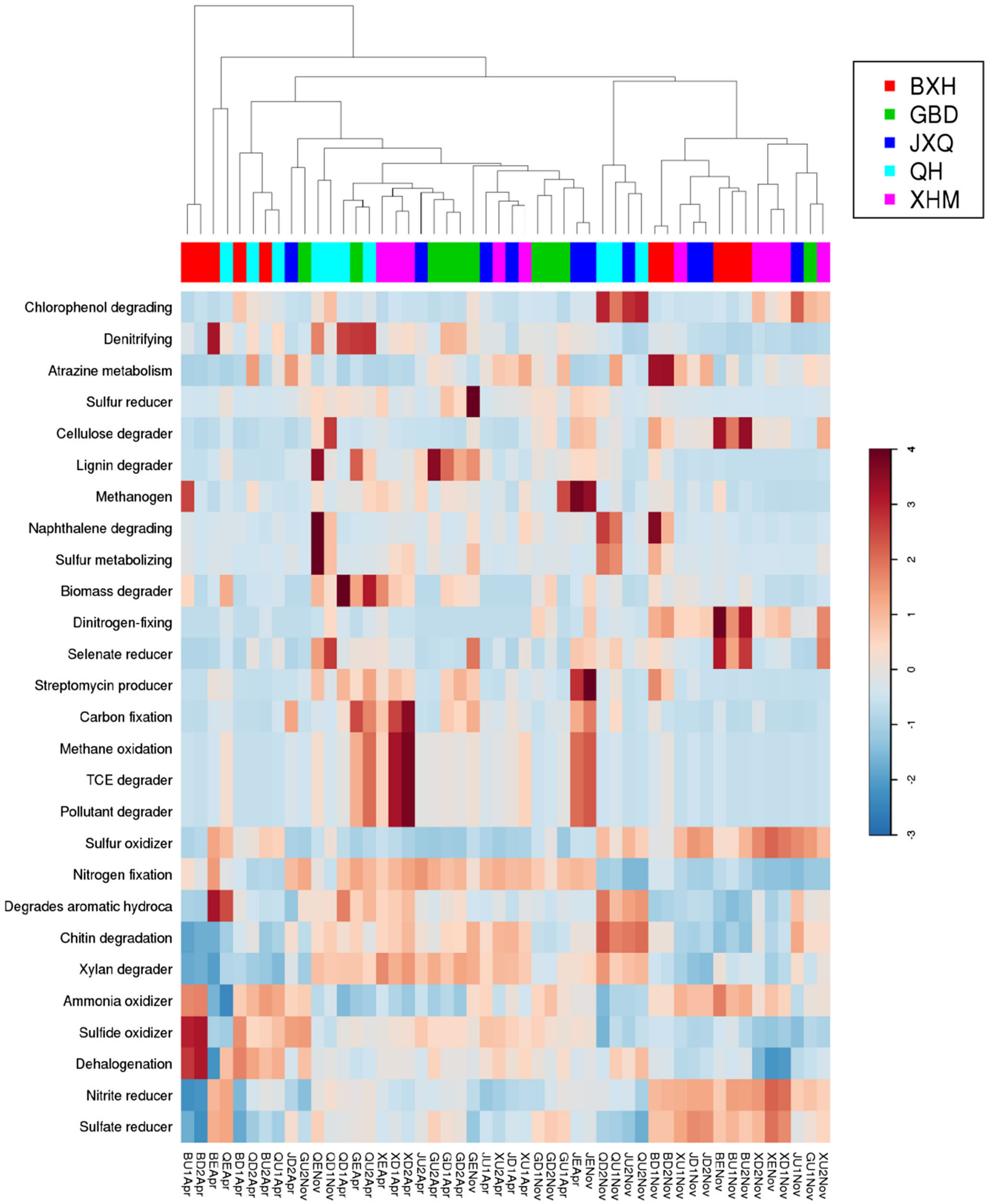

Fig. 3 Heatmap showing changes in the relative abundances of functional taxa across all samples grouped by different locations. The BIOM file produced by the QIIME was uploaded to the METAGENassist web server. Data were then filtered based on interquartile range. The remaining taxa were normalized over samples by sum, which adjusted for varying sequencing coverage among samples by normalizing to the same total abundance for each sample. Data were then analyzed for "metabolism by phenotype" and Euclidean distance measures and average clustering algorithms were used. Changes are visualized on a relative scale, with enrichment in red and depletion in blue 
Fig. 4 Redundancy analysis (RDA) biplot of bacterial communities at the class level in association with environmental variables. The ten classes that best fit the analysis are displayed

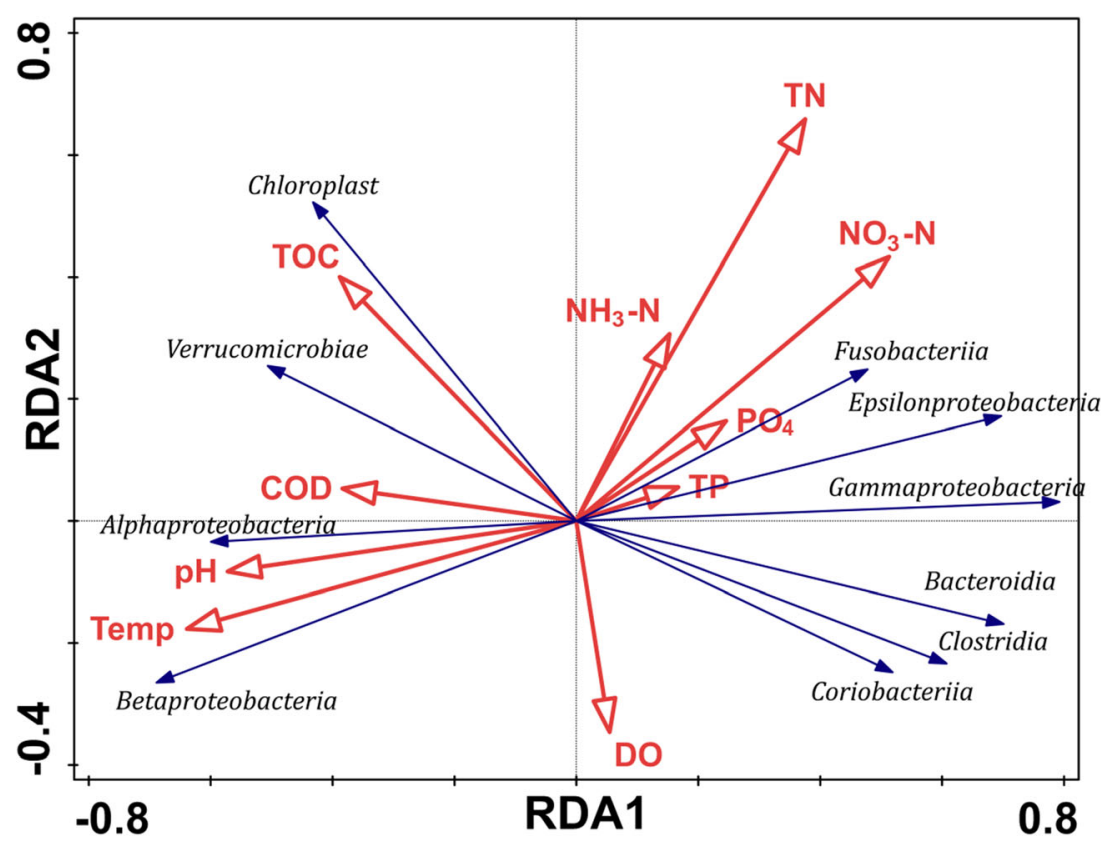

were also found between Bacilli and TOC $(r=-0.29, P=0.04)$ and between Cytophagia and DO $(r=-0.25, P=0.08)$, but with lower statistical significance.

\section{Quantitative analysis of 16S rRNA and amoA genes}

The abundances of archaeal 16S rRNA, bacterial 16S rRNA, and $a m o A$ genes in different water samples are shown in Fig. S5. The copy number of the bacterial 16S rRNA gene was higher than that of the archaeal 16S rRNA gene in almost all samples. The amoA results revealed the dominance of AOB rather than AOA in all environmental samples, with the $\mathrm{AOB} / \mathrm{AOA}$ ratios ranging from 8.07 to 184.44 . The amoA/16S rRNA ratio in the five WWTP effluents and rivers ranged from $10^{-1}$ to $10^{-4}$. A non-linear relationship between ammonium concentration and AOB abundance was found, whereas there seemed a possibly downward trend of $\mathrm{AOB}$ with increases of ammonium (Fig. 5a). A significant positive
Fig. 5 Scatter plots illustrating the relationship between copy number of ammonia-oxidizing microbes and concentration of ammonium/nitrate, including $\mathrm{AOB}$ and ammonium (a), $\mathrm{AOB}$ and nitrate (b), $\mathrm{AOB} / \mathrm{AOA}$ and ammonium (c), and $\mathrm{AOB} / \mathrm{AOA}$ and nitrate (d) a
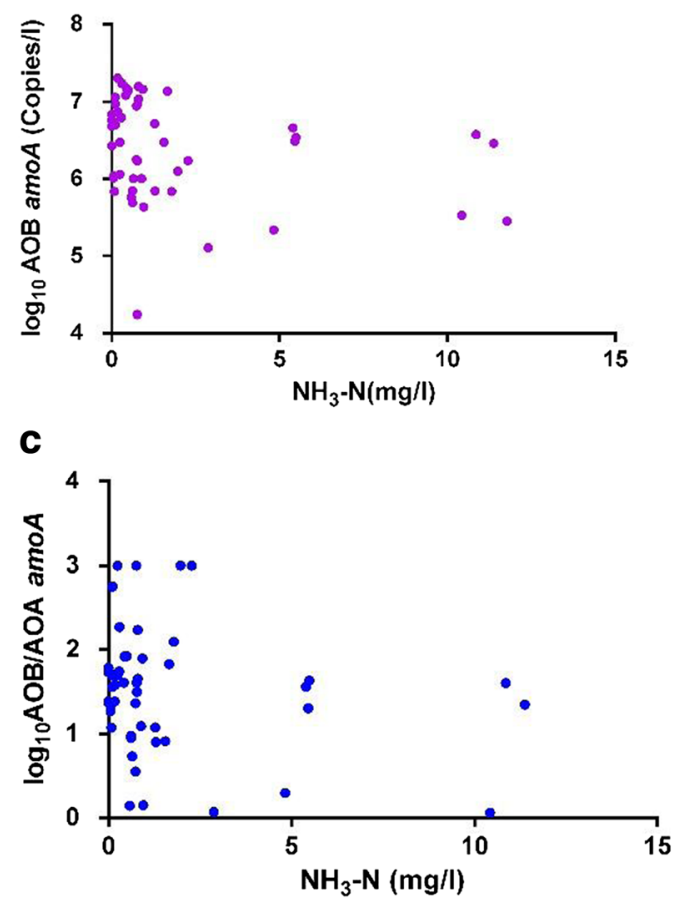

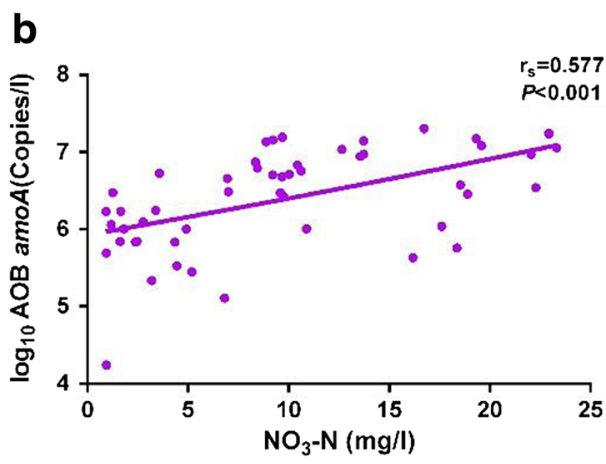

d

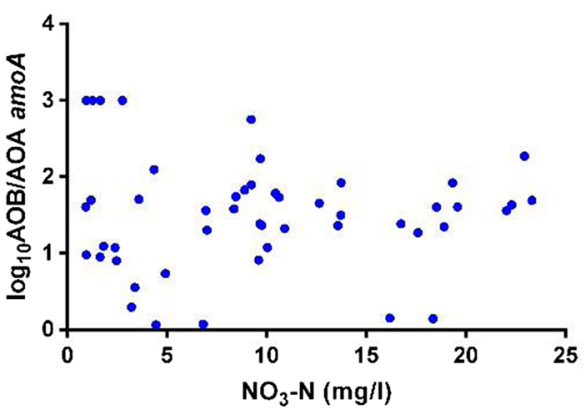


correlation between $\mathrm{AOB}$ and nitrate concentration was identified (Fig. 5b). The abundance ratio of AOB to AOA showed almost no relationship with ammonium and nitrate concentrations (Fig. 5c, d). These results demonstrated that AOB were the dominant ammonia-oxidizing microbes in all effluents and river samples. The abundance of AOB was associated with levels of nitrate in the effluents and rivers although the dominance over AOA did not change with the concentrations of both ammonium and nitrate.

\section{Discussion}

The objective of this study was to understand the impact of WWTP discharge on the composition and function of urban riverine microbial communities. Previous studies have reported both an increase (Goni-Urriza et al. 1999; Wakelin et al. 2008) and decrease (Drury et al. 2013) in downstream riverine microbial diversity with the impact of WWTP effluent. In our study, however, we did not observe significant differences in the microbial community from almost all upstream to downstream sites of these receiving rivers impacted by WWTPs in both sampling seasons. We considered that this similarity is mainly because of the receiving rivers being dominant by discharged WWTP effluent. First, as Beijing has encountered long-term water scarcity notably during the recent couple of decades, effluent from WWTPs rather than rainfall has been the major water source of these rivers in the urban area; second, the average velocity of effluent discharge is over 7.5 times higher than the velocity of the receiving river, which could bring effluent flow into these upstream sites. Furthermore, potential sources listed in Fig. S1 may contribute pollutants such as nutrients to the river and could cause similar water quality along the sampling sites. Through the NMDS analysis, we also found that the microbial community composition in the majority of the effluents falls in a similar range, indicating that the microbial community shifts along the upstream and the downstream is likely not caused by treatment technology (Fig. 1). Member profiling of the microbial communities revealed dominant abundance of Proteobacteria, except for the Comamonadaceae family that belonged to the Proteobacteria that has been frequently reported in river ecosystems (Cai et al. 2016; Crump et al. 2009). The genus Arcobacter, another member of the Proteobacteria, has been reported as potential human pathogens (Fisher et al. 2014). Bacteroidetes in freshwater ecosystems are known to degrade organic compounds with high molecular weight (Thomas et al. 2011). Therefore, the higher abundance of Bacteroidetes indicates the result of complex organic compounds with higher concentration in the sampling sites (Drury et al. 2013). For the upstream of Xiaohongmen in April, Chloroplast was richer because of the large nutrient load at that time. Chloroplast belonged to the Cyanobacteria phylum and Cyanobacteria proliferation is mainly associated with water body eutrophication (Riedinger-Whitmore et al. 2005). These results revealed that the effluent-dominated rivers with heavy pollution negatively affect the safety of river in a microbial ecological context.

Through the workflow of METAGENassist and PICRUSt, we annotated the microbial functional features for the WWTP effluent and river samples. Notably, several xenobiotic degradation functions were identified in the effluent and river samples, as also reported in WWTP effluent and river samples using shotgun metagenome sequencing (Bai et al. 2014). In this study, it is still unclear to what extent the abundance of $16 \mathrm{~S}$ sequences that likely encoding these functional genes shifted between effluents and samples with different concentrations of toxicants, or whether these related genes in the effluent were still expressed once they migrated to the rivers. One recent study found that functional genes associated with xenobiotic, carbohydrate, and amino acid metabolism were overrepresented in upstream and deep downstream river sediments. By contrast, wastewater discharge in shallow downstream sediments resulted in an increase in genes associated with nitrogen, sulfur, purine, and pyrimidine metabolism ( $\mathrm{Li}$ et al. 2016). Another recent study showed that toxic chemicals increased the microbial metabolic enzymes and pathways, and polycyclic aromatic hydrocarbons and nitrobenzene were negatively correlated with bacterial community variation ( $\mathrm{Lu}$ et al. 2016). However, further investigations are needed to understand the flow and impact of these functional genes on the relationship between wastewater discharge and receiving rivers.

In this study, bacterial and archaeal amoA genes were detected using real-time PCR. Ammonia oxidation by functional $\mathrm{AOA}$ and $\mathrm{AOB}$ is the key rate-limiting step of the nitrogen cycle and therefore plays an important role in riverine ecosystem function. Previous research has demonstrated that the biotransformation kinetics of pollutants during WWTP treatment are associated with the activity of the amoA gene, rather than WWTP process parameters (Helbling et al. 2012). The larger copy number of AOB amoA genes in both WWTP effluent and river water samples demonstrated the dominance of $\mathrm{AOB}$ in ammonia oxidation, in accordance with recent research (Lee et al. 2016). Earlier studies also revealed higher abundances of AOA in river ecosystems (Zhang et al. 2015), and the dominance of AOB was found in WWTP effluent (Gao et al. 2014; Sonthiphand et al. 2013) and rivers (Mosier and Francis 2008; Santoro et al. 2008; Wankel et al. 2011). Here, correlation analysis demonstrated significant associations between $\mathrm{AOB}$ and nitrate concentration. The greater number of $\mathrm{AOB}$ amoA gene copies over that of AOA suggests that $\mathrm{AOB}$ are a major contributor to nitrification (Magalhães et al. 2009).

This study provided structural and functional insights into the microbial communities of urban river ecosystems experiencing heavy anthropogenic stresses. With the rapid 
development of high-throughput sequencing technologies and increasing advances in the Earth microbiome project, further exploration of microbial communities will continue to improve our understanding of microbial responses and processes to a wide range of pollutants in water bodies.

Acknowledgements This work was supported by the National Natural Science Foundation of China (Funding No. 51420105012 and 51578537) and the Chinese Academy of sciences (ZDRW-ZS-2016-5-6). The authors thank the BGI Central China (Wuhan) for high-throughput sequencing services. We also kindly thank the other members of the EcoImprove team for their help in the sampling.

\section{Compliance with ethical standards}

Conflict of interest The authors declare that they have no conflict of interest.

Ethical approval This article does not contain any studies with human participants or animals performed by any of the authors.

\section{References}

Arndt D, Xia JG, Liu YF, Zhou Y, Guo AC, Cruz JA, Sinelnikov I, Budwill K, Nesbo CL, Wishart DS (2012) METAGENassist: a comprehensive web server for comparative metagenomics. Nucleic Acids Res 40(W1):W88-W95

Asshauer KP, Wemheuer B, Daniel R, Meinicke P (2015) Tax4Fun: predicting functional profiles from metagenomic $16 \mathrm{~S}$ rRNA data. Bioinformatics 31(17):2882-2884

Atashgahi S, Aydin R, Dimitrov MR, Sipkema D, Hamonts K, Lahti L, Maphosa F, Kruse T, Saccenti E, Springael D, Dejonghe W, Smidt H (2015) Impact of a wastewater treatment plant on microbial community composition and function in a hyporheic zone of a eutrophic river. Sci Rep-Uk 5:17284. doi: 10.1038/Srep17284

Bai YH, Sun QH, Wen DH, Tang XY (2012) Abundance of ammoniaoxidizing bacteria and archaea in industrial and domestic wastewater treatment systems. FEMS Microbiol Ecol 80(2):323-330

Bai YH, Qi WX, Liang JS, Qu JH (2014) Using high-throughput sequencing to assess the impacts of treated and untreated wastewater discharge on prokaryotic communities in an urban river. Appl Microbiol Biot 98(4):1841-1851

Brooks BW, Riley TM, Taylor RD (2006) Water quality of effluentdominated ecosystems: ecotoxicological, hydrological, and management considerations. Hydrobiologia 556:365-379

Bunzel K, Kattwinkel M, Liess M (2013) Effects of organic pollutants from wastewater treatment plants on aquatic invertebrate communities. Water Res 47(2):597-606

Cai W, Li Y, Wang P, Niu L, Zhang W, Wang C (2016) Effect of the pollution level on the functional bacterial groups aiming at degrading bisphenol A and nonylphenol in natural biofilms of an urban river. Environ Sci Pollut Res. doi:10.1007/s11356-016-6757-3

Caporaso JG, Kuczynski J, Stombaugh J, Bittinger K, Bushman FD, Costello EK, Fierer N, Pena AG, Goodrich JK, Gordon JI, Huttley GA, Kelley ST, Knights D, Koenig JE, Ley RE, Lozupone CA, McDonald D, Muegge BD, Pirrung M, Reeder J, Sevinsky JR, Tumbaugh PJ, Walters WA, Widmann J, Yatsunenko T, Zaneveld J, Knight R (2010) QIIME allows analysis of high-throughput community sequencing data. Nat Methods 7(5):335-336

Chao A (1987) Estimating the population-size for capture recapture data with unequal catchability. Biometrics 43(4):783-791
Crump BC, Peterson BJ, Raymond PA, Amon RMW, Rinehart A, McClelland JW, Holmes RM (2009) Circumpolar synchrony in big river bacterioplankton. P Natl Acad Sci USA 106(50):2120821212

DeSantis TZ, Hugenholtz P, Larsen N, Rojas M, Brodie EL, Keller K, Huber T, Dalevi D, Hu P, Andersen GL (2006) Greengenes, a chimera-checked 16S rRNA gene database and workbench compatible with ARB. Appl Environ Microb 72(7):5069-5072

Drury B, Rosi-Marshall E, Kelly JJ (2013) Wastewater treatment effluent reduces the abundance and diversity of benthic bacterial communities in urban and suburban rivers. Appl Environ Microb 79(6):18971905

Dyer SD, Peng C, McAvoy DC, Fendinger NJ, Masscheleyn P, Castillo LV, Lim JMU (2003) The influence of untreated wastewater to aquatic communities in the Balatuin River, The Philippines. Chemosphere 52(1):43-53

Edgar RC (2010) Search and clustering orders of magnitude faster than BLAST. Bioinformatics 26(19):2460-2461

Edgar RC (2013) UPARSE: highly accurate OTU sequences from microbial amplicon reads. Nat methods 10(10):996-998

Fisher JC, Levican A, Figueras MJ, McLellan SL (2014) Population dynamics and ecology of Arcobacter in sewage. Front Microbiol 5:525. doi: 10.3389/fmicb.2014.00525

Gao J, Luo X, Wu G, Li T, Peng Y (2014) Abundance and diversity based on amoA genes of ammonia-oxidizing archaea and bacteria in ten wastewater treatment systems. Appl Microbiol Biot 98(7):33393354

Glejser H (1969) A new test for heteroskedasticity. J Am Stat Assoc 64(325):316-323

Goni-Urriza M, Capdepuy M, Raymond N, Quentin C, Caumette P (1999) Impact of an urban effluent on the bacterial community structure in the Arga River (Spain), with special reference to culturable gram-negative rods. Can J Microbiol 45(10):826-832

Gucker B, Brauns M, Pusch MT (2006) Effects of wastewater treatment plant discharge on ecosystem structure and function of lowland streams. J N Am Benthol Soc 25(2):313-329

Helbling DE, Johnson DR, Honti M, Fenner K (2012) Micropollutant biotransformation kinetics associate with WWTP process parameters and microbial community characteristics. Environ Sci Technol 46(19):10579-10588

Langille MGI, Zaneveld J, Caporaso JG, McDonald D, Knights D, Reyes JA, Clemente JC, Burkepile DE, Vega Thurber RL, Knight R, Beiko RG, Huttenhower C (2013) Predictive functional profiling of microbial communities using 16S rRNA marker gene sequences. Nat Biotechnol 31(9):814-821

Lee K-H, Wang Y-F, Wang Y, Gu J-D, Jiao JJ (2016) Abundance and diversity of aerobic/anaerobic ammonia/ammonium-oxidizing microorganisms in an ammonium-rich aquitard in the Pearl River Delta of South China. Microb Ecol:1-11

Li D, Sharp JO, Drewes JE (2016) Influence of wastewater discharge on the metabolic potential of the microbial community in river sediments. Microb Ecol 71(1):78-86

Logue JB, Stedmon CA, Kellerman AM, Nielsen NJ, Andersson AF, Laudon H, Lindström ES, Kritzberg ES (2016) Experimental insights into the importance of aquatic bacterial community composition to the degradation of dissolved organic matter. The ISME Journal 10(3):533-545

Lu X-M, Chen C, Zheng T-L (2016) Metagenomic insights into effects of chemical pollutants on microbial community composition and function in estuarine sediments receiving polluted river water. Microb Ecol:1-10

Magalhães CM, Machado A, Bordalo AA (2009) Temporal variability in the abundance of ammonia-oxidizing bacteria vs. archaea in sandy sediments of the Douro River estuary, Portugal. Aquat Microb Ecol $56(1): 13-23$ 
Marti E, Balcazar JL (2014) Use of pyrosequencing to explore the benthic bacterial community structure in a river impacted by wastewater treatment plant discharges. Res Microbiol 165(6):468-471

McClain ME, Boyer EW, Dent CL, Gergel SE, Grimm NB, Groffman PM, Hart SC, Harvey JW, Johnston CA, Mayorga E, McDowell WH, Pinay G (2003) Biogeochemical hot spots and hot moments at the interface of terrestrial and aquatic ecosystems. Ecosystems 6(4):301-312

Mosier AC, Francis CA (2008) Relative abundance and diversity of ammonia-oxidizing archaea and bacteria in the San Francisco Bay estuary. Environ Microbiol 10(11):3002-3016

Noble RT, Fuhrman JA (1998) Use of SYBR Green I for rapid epifluorescence counts of marine viruses and bacteria. Aquat Microb Ecol 14(2):113-118

Parks DH, Tyson GW, Hugenholtz P, Beiko RG (2014) STAMP: statistical analysis of taxonomic and functional profiles. Bioinformatics 30(21):3123-3124

Pernet-Coudrier B, Qi WX, Liu HJ, Muller B, Berg M (2012) Sources and pathways of nutrients in the semi-arid region of Beijing Tianjin, China. Environ Sci Technol 46(10):5294-5301

Prat N, Rieradevall M, Barata C, Munne A (2013) The combined use of metrics of biological quality and biomarkers to detect the effects of reclaimed water on macroinvertebrate assemblages in the lower part of a polluted Mediterranean river (Llobregat River, NE Spain). Ecol Indic 24:167-176

Pylro VS, Roesch LFW, Morais DK, Clark IM, Hirsch PR, Tótola MR (2014) Data analysis for 16S microbial profiling from different benchtop sequencing platforms. J Microbiol Methods 107:30-37

Qi WX, Singer H, Berg M, Muller B, Pernet-Coudrier B, Liu HJ, Qu JH (2015) Elimination of polar micropollutants and anthropogenic markers by wastewater treatment in Beijing, China. Chemosphere 119:1054-1061

Riedinger-Whitmore MA, Whitmore TJ, Smoak JM, Brenner M, Moore A, Curtis J, Schelske CL (2005) Cyanobacterial proliferation is a recent response to eutrophication in many Florida lakes: a paleolimnological assessment. Lake Reserv Manage 21(4):423-435

Santoro AE, Francis CA, De Sieyes NR, Boehm AB (2008) Shifts in the relative abundance of ammonia-oxidizing bacteria and archaea across physicochemical gradients in a subterranean estuary. Environ Microbiol 10(4):1068-1079
Schwarzenbach RP, Escher BI, Fenner K, Hofstetter TB, Johnson CA, von Gunten U, Wehrli B (2006) The challenge of micropollutants in aquatic systems. Science 313(5790):1072-1077

Sergeant MJ, Constantinidou C, Cogan T, Penn CW, Pallen MJ (2012) High-throughput sequencing of 16S rRNA gene amplicons: effects of extraction procedure, primer length and annealing temperature. PLoS One 7(5):e38094

Sonthiphand P, Cejudo E, Schiff SL, Neufeld JD (2013) Wastewater effluent impacts ammonia-oxidizing prokaryotes of the Grand River, Canada. Appl Environ Microb 79(23):7454-7465

Spanhoff B, Bischof R, Bohme A, Lorenz S, Neumeister K, Nothlich A, Kusel K (2007) Assessing the impact of effluents from a modern wastewater treatment plant on breakdown of coarse particulate organic matter and benthic macroinvertebrates in a lowland river. Water Air Soil Poll 180(1-4):119-129

Tank JL, Rosi-Marshall EJ, Griffiths NA, Entrekin SA, Stephen ML (2010) A review of allochthonous organic matter dynamics and metabolism in streams. J N Am Benthol Soc 29(1):118-146

Thomas F, Hehemann J-H, Rebuffet E, Czjzek M, Michel G (2011) Environmental and gut Bacteroidetes: the food connection. Front Microbiol 2(93). doi:10.3389/fmicb.2011.00093

Waiser MJ, Tumber V, Holm J (2011) Effluent-dominated streams. Part 1: presence and effects of excess nitrogen and phosphorus in Wascana Creek, Saskatchewan. Canada Environ Toxicol Chem 30(2):496507

Wakelin SA, Colloff MJ, Kookana RS (2008) Effect of wastewater treatment plant effluent on microbial function and community structure in the sediment of a freshwater stream with variable seasonal flow. Appl Environ Microb 74(9):2659-2668

Wankel SD, Mosier AC, Hansel CM, Paytan A, Francis CA (2011) Spatial variability in nitrification rates and ammonia-oxidizing microbial communities in the agriculturally impacted Elkhorn Slough Estuary, California. Appl Environ Microb 77(1):269-280

Wright IA, Chessman BC, Fairweather PG, Benson LJ (1995) Measuring the impact of sewage effluent on the macroinvertebrate community of an upland stream - the effect of different levels of taxonomic resolution and quantification. Aust J Ecol 20(1):142-149

Zhang Q, Tang F, Zhou Y, Xu J, Chen H, Wang M, Laanbroek HJ (2015) Shifts in the pelagic ammonia-oxidizing microbial communities along the eutrophic estuary of Yong River in Ningbo City, China. Front Microbiol 6:1180 